\title{
Reduction of connexin 37 expression by RNA interference decreases atherosclerotic plaque formation
}

\author{
SUXIA GUO ${ }^{1,2^{*}}$, JIHONG ZHU $^{3 *}$, ZHENYU YANG $^{2}$, JIAN FENG $^{2}$, \\ KULIN LI ${ }^{2}$, RUXING WANG ${ }^{2}$ and XIANGJUN YANG ${ }^{1}$ \\ ${ }^{1}$ Department of Cardiology, The First Affiliated Hospital of Soochow University, Suzhou, Jiangsu 215006; \\ ${ }^{2}$ Department of Cardiology, The Affiliated Hospital of Nanjing Medical University, Wuxi People's Hospital, Wuxi, Jiangsu 214023; \\ ${ }^{3}$ Department of Cardiovascular Medicine, The First AffiliatedHospital of Henan University of Science and Technology, \\ Luoyang, Henan 471003, P.R. China
}

Received October 31, 2013; Accepted June 5, 2014

DOI: $10.3892 / \mathrm{mmr} .2014 .3053$

\begin{abstract}
The aim of this study was to examine the effects of connexin 37 (Cx37) interference on atherosclerotic plaques. Lentiviruses expressing small interfering RNA (siRNA) of Cx 37 were constructed, and were shown to significantly knockdown the mRNA and protein expression of Cx37 in vitro. Sixty pigs on a high-fat diet were randomly divided into three treatment groups of saline, mock or Cx37 siRNA, to induce plaque formation. The $\mathrm{Cx} 37$ lentiviral suspension was transfected into the abdominal aortic plaques of pigs. Plaque characteristics were detected by intravascular ultrasound and the expression of Cx37 mRNA was detected by semi-quantitative polymerase chain reaction. The expression of $\mathrm{Cx} 37$ protein was analyzed by western blot analysis. Two months after lentivirus transfection, Cx37 mRNA levels were decreased by $38 \%$ in the Cx37 siRNA group, by $60 \%$ in the mock-siRNA group and by $63 \%$ in the saline group $(\mathrm{P}<0.05)$. The mock group showed no significant changes in $\mathrm{Cx} 37$ expression as compared with the saline group. $\mathrm{Cx} 37$ protein expression was lower in the Cx37 siRNA-treated group as compared with the other groups $(0.21 \pm 0.07$ vs. $0.65 \pm 0.06$ vs. $0.54 \pm 0.07)$. The percentage of plaque necrosis at 10 months (two months following RNAi) was decreased in the Cx37 siRNA group as compared with
\end{abstract}

Correspondence to: Professor Zhenyu Yang, Department of Cardiology, The Affiliated Hospital of Nanjing Medical University, Wuxi People's Hospital, 299 Qingyang Road, Wuxi, Jiangsu 214023, P.R. China

E-mail: suxiaguodoc@163.com

Professor Xiangjun Yang, Department of Cardiology, The First Affiliated Hospital of Soochow University, 296 Shizi Street, Suzhou, Jiangsu 215006, P.R. China

E-mail: xiangjuny@yeah.net

${ }^{*}$ Contributed equally

Key words: atherosclerosis, gene therapy, plaques, connexin 37, small interfering RNA that at eight months, prior to RNAi $(5.26 \pm 2.11$ vs. $7.83 \pm 1.03 \%$, $\mathrm{P}<0.05)$. In the mock-siRNA and saline groups, no differences $(P=0.074,0.061$, respectively) were observed. In the Cx37 siRNA group, plaque volumes following 10 months decreased relative to those following eight months, prior to RNAi $(21.03 \pm 6.24$ vs. $31.23 \pm 10.23, \mathrm{P}<0.01)$. By contrast, in the mock siRNA and saline groups, plaque volumes after 10 months were increased relative to those following eight months $\left(38.54 \pm 13.56\right.$ vs. $32.12 \pm 11.21 \mathrm{~mm}^{3}, 37.36 \pm 14.21$ vs. $\left.30.21 \pm 12.02 \mathrm{~mm}^{3}, \mathrm{P}=0.031, \mathrm{P}=0.027\right)$. Atherosclerotic plaque formation was effectively decreased through the downregulation of Cx37 mRNA using Cx37 siRNA.

\section{Introduction}

Atherosclerosis is a chronic inflammatory disease of the artery wall, which involves multiple cell types of different origins, and complex intracellular interactions and signaling pathways (1-3). Understanding the function of genes involved in atherosclerosis has been given much attention by scientists and clinicians over recent years (4). Connexins are members of a family of proteins encoded by at least 20 different mammalian genes, and are expressed in a wide variety of tissues (5-7). Connexins form transmembrane channels known as gap junctions, which connect neighboring cells and allow passive diffusion of small molecules (8). Connexin 37 (Cx37) is a junction protein that has a central function in initiating the inflammatory response. In a previous study by our group (9), it was found that the $\mathrm{C}$ allele of the $\mathrm{Cx} 37$ gene is associated with susceptibility to coronary heart disease, particularly in the male population. Boerma et al (10) identified a link between a single nucleotide polymorphism (SNP) in the human Cx37 gene and a thickening of the carotid artery in the Swedish male population, in which the $\mathrm{C}$ allele was over-represented in individuals with atherosclerotic plaques. The $\mathrm{C}$ allele of this SNP has also been associated with coronary heart disease in individuals from Taiwan, northern China and Switzerland (11-13). Subsequently, two studies performed on Japanese and Caucasian populations revealed that T-SNP is a risk factor for acute myocardial infarction (AMI), particularly in high-risk male individuals $(14,15)$. Seifi et al (16) suggested 
that the polymorphism in the $\mathrm{Cx} 37$ gene has a significant effect on the manifestation of AMI disease in Iranian individuals. However, Cx37 deletion in apolipoprotein E-deficient mice was shown to increase susceptibility to atherosclerosis (17).

Gene knockout studies have identified that Cx37 forms gap junction channels between endothelial cells. Two polymorphic Cx37 variants (Cx37-S319 and Cx37-P319) have been identified with a possible link to atherosclerosis (18). Although these results are encouraging, the relative contribution and synergistic effects of $\mathrm{Cx} 37$ on the formation of atherosclerotic plaques remain elusive. The present study therefore hypothesized that Cx37 may affect atherosclerotic plaque formation.

Schecter et al (19) delivered small interfering RNAs (siRNAs) with lentiviruses, which have proven to be effective in silencing target genes by means of RNA interference (RNAi). A previous study showed that atherosclerosis in a pig model was most similar to the condition in humans (20). In the present study, a lentiviral vector was constructed to knockdown $\mathrm{Cx} 37$ and elucidate its role in effecting atherosclerotic plaques in pigs. This vector was observed by intravascular ultrasound (IVUS).

\section{Materials and methods}

Cell culture. HEK 293 cells were obtained from the Cell Bank of the Chinese Academy of Science (Beijing, China). The cells were cultured using previously reported methods (21), and maintained at $37^{\circ} \mathrm{C}$, with $5 \% \mathrm{CO}_{2}$ in complete RPMI medium (Gibco-BRL, Carlsbad, CA, USA). When the cell fusion rate reached $90 \%$, the cells were divided at a ratio of 1:4 and frozen in the logarithmic growth phase. Cell recovery took place when the cells did not grow efficiently.

Preparation of lentiviral vectors and target screening for RNAi. Three different sequences (sites A, B and C) of the pig Cx37 gene were selected from GenBank as a target for RNAi. The targeted sequence of mm-cx37-si-1 was as follows: 5'-GGUUAACGGUGCUCUUCAU-'3 location: 209; Targeted sequence of mm-cx37-si-2: 5'-CCA AGGACCUACAUGUAGA-'3 location: 488; Targeted sequence of mm-cx37-si-3: 5'- CAGACCCUUACCCUGAACA-'3 location: 841. A FLAG-tagged expression construct for the full length $\mathrm{Cx} 37$ sequence was additionally constructed and an empty p3xFlag vector was used as a negative control. The vector construct is shown diagramatically in Fig. 1.

All cells were divided into six groups. The experimental groups were comprised of i) overexpression of empty p3xflag plasmid $(0.4 \mu \mathrm{g})$, ii) p3xflag-Cx37 expression plasmid $(0.4 \mu \mathrm{g})$, and iii-v) p3xflag-Cx37 expression plasmid $(0.4 \mu \mathrm{g})$ with one of the three different interference fragments. The respective interference fragments were used at a concentration of $50 \mathrm{nM}$ and the transfection time was $72 \mathrm{~h}$. Constructs were transfected using Lipofectamine ${ }^{\mathrm{TM}} 2000$ (Invitrogen Life Technologies, Carlsbad, CA, USA). The wild-type Cx37 interference construct, the negative control and p3xflag-Cx37 were cotransfected with RNAi plasmids and mixed at a molar ratio of 5:1. The best interference fragment was selected based on the results from the western blotting. The preparation of lentiviral vectors expressing Cx37 involved the use of BLOCK-It Lentiviral Pol II miR RNAi Expression system with green fluorescence protein (GFP; Catalog No. K493800; Invitrogen). A scrambled siRNA sequence (named mock-siRNA) with no known homology to mammal genes served as control.

Cells were collected $72 \mathrm{~h}$ after transfection and washed three times with cold phosphate-buffered saline (PBS). A total of $0.2 \mathrm{ml}$ radioimmunoprecipitation assay buffer containing a protease inhibitor mixture was added, and the cells were incubated on ice for $30 \mathrm{~min}$. Finally, $1.5 \mathrm{ml}$ cells were collected using a cell scraper and transferred to a centrifuge tube on ice. Ultrasonic lysis of the cells was performed for $30 \mathrm{sec}$ at $4^{\circ} \mathrm{C}$. The supernatant was centrifuged at 22,500 x g for $30 \mathrm{~min}$, and then transferred to a new microcentrifuge tube and stored at $-20^{\circ} \mathrm{C}$.

Third, protein concentrations were determined using a bicinchoninic acid (BCA) assay (Pierce Biotechnology, Rockford, IL, USA). Solutions A and B from the BCA kit were mixed at a 50:1 ratio and incubated at room temperature for $30 \mathrm{~min}$. Then, $200 \mu \mathrm{l}$ of the combined solution were added to each well of a 96-well plate, as well as $10 \mu \mathrm{l}$ of a concentration range of bovine serum albumin at a 1:10 dilution. A blank using $10 \mu \mathrm{l}$ double-distilled water was used to normalize to zero. The plate was incubated at $37^{\circ} \mathrm{C}$ for $30 \mathrm{~min}$ in the microplate reader (SPECTROstar Omega; BMG Labtech GMBH, Ortenberg, Germany) to determine the $570 \mathrm{~nm}$ absorbance value. A standard curve was generated and the concentration of total protein sample was calculated.

Western blot analysis. The total cellular protein of aortic plaque tissue of pigs was extracted. 10\% SDS-PAGE of the sample was performed. The protein was transferred to the collodion membrane, followed by blocking. The membrane was incubated with primary antibody (anti-Cx37 antibody, 1:200, Abcam, Cambridge, MA, USA) at $4^{\circ} \mathrm{C}$ overnight. Following washing for three times, the membrane was incubated with secondary antibody $(1: 2,000)$ for $1 \mathrm{~h}$, followed by washing for three times. Protein expression was quantified using an using enhanced chemiluminescence detection kit (Beijing Kang Century Biotech Co., Ltd., Beijing, China).

Animal maintenance and set-up of experimental groups. Sixty male Wuzhishan small pigs (four weeks old) were obtained from Wuzhishan Pig Breeding Farm (Hainan, China). The pigs were provided with a normal diet and water. After one week, the pigs received a high-fat diet (5\% lard, $1 \%$ sugar, $3 \%$ cholesterol and $0.2 \%$ propylthiouracil) and fed three times daily. All pigs were consistently provided with a high-fat diet for 10 months. This study was carried out in strict accordance with the recommendations of the Guide for the Care and Use of Laboratory Animals of the National Institute of Health. The animal use protocol was reviewed and approved by the Institutional Animal Care and Use Committee of the Affiliated Hospital of Nanjing Medical University Wuxi People's Hospital (Wuxi, China). The pigs were divided into three groups; (1) Cx37 siRNA-treated group with an infusion of $10 \mathrm{pl} \mathrm{Cx37} \mathrm{lentiviral} \mathrm{suspension,} \mathrm{(2)} \mathrm{Mock,} \mathrm{untreated} \mathrm{group,}$ and (3) Saline-treated group. These 3 groups received the corresponding treatment for the last 2 months of 10 months, respectively. The mock siRNA and saline treatment groups did not receive any viral infusion. After two months of treatment, abdominal aortic angiography and IVUS were performed 
in all pigs. The plaque of aortic atherosclerosis in pigs was observed under microscope (DM750; Leica Microsystems $\mathrm{GmbH}$, Wetzlar, Germany) and analyzed according to reported method (22). The expression of Cx37 mRNA was detected by semi-quantiative PCR according to a reported method (9). The expression of $\mathrm{Cx} 37$ protein was determined by western blot analysis.

Abdominal aortic angiography and IVUS analysis. After eight months of the experimental protocol, abdominal aortic angiography and IVUS were performed on all pigs under anesthesia by intravenous injection of ketamine hydrochloride. All IVUS images were acquired using a $20 \mathrm{MHz}$ Volcano Eagle Eye $^{\mathrm{TM}}$ IVUS catheter (Volcano Therapeutics, Inc., Rancho Cordova, CA, USA). Once the abdominal aorta lesion had been identified, the IVUS catheter was inserted distal to the lesion and automatically pulled back to assess the severity and length of the lesion (rate of $0.5 \mathrm{~mm} / \mathrm{sec}$ ). The location of the IVUS catheter was determined using continuous fluoroscopy throughout the time of pullback, as well as by recording anatomical landmarks observed during IVUS imaging. To create adequate images, an average of two pullbacks per artery was performed. Subsequently, the best play loop was selected based on imaging resolution and quality. Continuous electrocardiography monitoring was performed during the procedure to gate the IVUS frames for analysis. IVUS-virtual histology (VH) data were recorded on the imaging system hard drive and then extracted and archived for analysis. Analysis was based on border contour calculation from greyscale. Tissue maps provided by the software (dark green for fibrous tissue, light green for fibrofatty tissue, red for necrotic core and white for dense calcium) were used to analyze each independent frame. Once the total length of each lesion had been determined, a $20 \mathrm{~mm}$ vascular segment containing the vascular lesion was selected for analysis. This segment was then divided into equal $2.0-\mathrm{mm}$ subsections, generating a total of 10 series of cross-sections per vascular segment. Then, the abdominal cavity was opened. An incision was made on the left paracolic sulci and side peritoneum, exposing the descending colon and its mesentery to the right, and exposing the abdominal aorta. Wire positioning was upstream to block blood flow. The aortic plaques were injected with Cx37 siRNA virus suspension and mock-siRNA virus suspension or saline and then the sutured vascular and abdominal areas were injected using a needle at $\sim 30^{\circ}$ angle.

Serum lipid level measurements. Detection of serum lipid was conducted by analysis of orbital venous sinus blood. The plasma levels of total cholesterol (TC), plasma triglyceride (TG), low- and high-density lipoprotein cholesterol (LDL-C and HDL-C, respectively) were measured by the oxidase method (Center Laboratory of Wuxi People's Hospital, Wuxi, China) (23).

Statistical analysis. Data are expressed as the mean \pm standard deviation. Continuous variables between two groups were compared using independent t-tests and $\chi^{2}$ tests. Multiple groups were compared by analysis of variance. All tests were conducted using SPSS 17.0 software for Windows (SPSS, Inc., Chicago, IL, USA). Proportions were compared using Fisher's

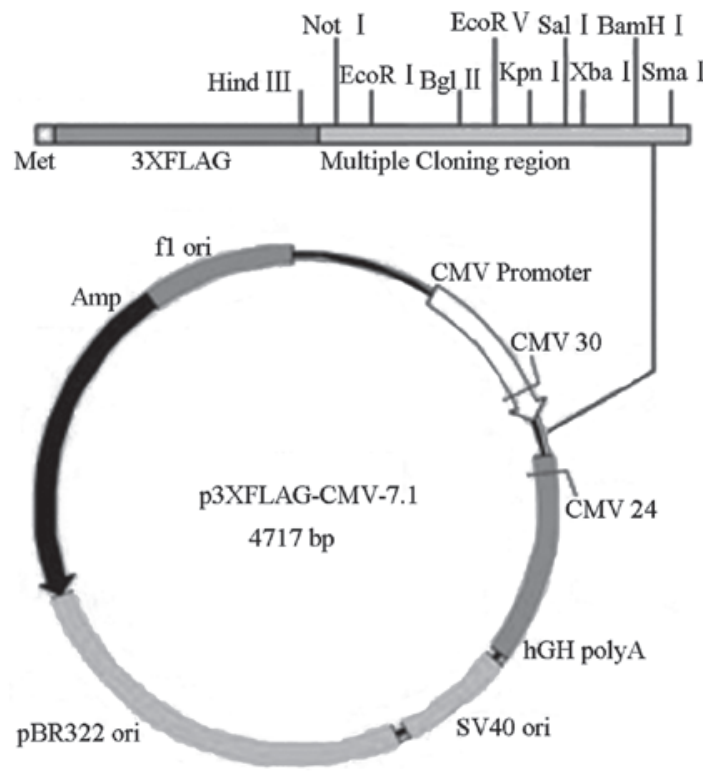

Figure 1. p3XFLAG-CMV-7.1 vector diagram.

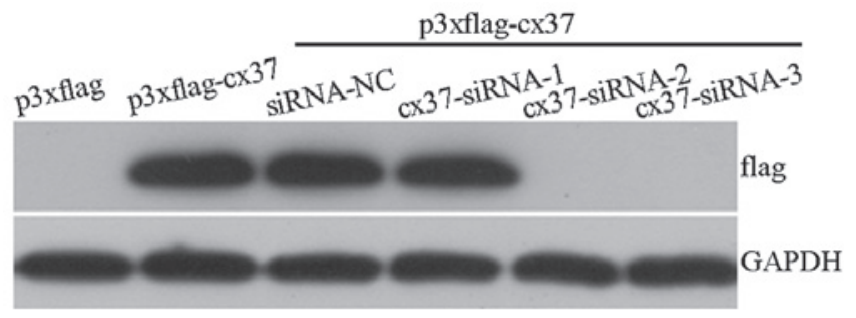

Figure 2. Western blot analysis of the efficiency of three Cx37 siRNAs in Cx37 silencing in vitro. $\mathrm{NC}$, negative control; siRNA, small interfering RNA; Cx37, connexin 37

exact test with expected frequency of $<5 . \chi^{2}$ testing was applied in all other cases. $\mathrm{P}<0.05$ was considered to indicate a statistically significant difference.

\section{Results}

Body weight and serum lipid profile. No significant differences were identified in body weight among the $\mathrm{Cx} 37$ siRNA group and untreated groups, e.g. the mock and saline subgroups. This indicated that the virus was safe to transfect with regard to the overall health status of the animals. Likewise, serum cholesterol and triglyceride levels in the treatment group did not differ significantly from those in the untreated groups (Table I). This finding suggested that the therapeutic effects of gene transfer were independent of serum lipid levels.

Gene silencing in vitro. The most effective targeting sites for siRNA in the Cx37 sequence were screened by western blot analysis (Fig. 2). HEK293 cells were transfected with lentivirus-based vectors expressing three different Cx37 siRNAs. Gene silencing analysis identified that the $\mathrm{Cx} 37$ lentivirus sequences 2 and 3 were the most effective vectors in blocking Cx37 expression. Consequently, Cx37-site 3 lentiviruses were selected for further in vivo studies. 
Table I. Change in body weight and serum lipid profiles.

Untreated groups

\begin{tabular}{llccc} 
& Time-point & Cx37 siRNA group $(\mathrm{n}=20)$ & Mock-siRNA $(\mathrm{n}=20)$ & Saline $(\mathrm{n}=20)$ \\
\hline Weight $(\mathrm{kg})$ & Baseline & $21.51 \pm 10.34(\mathrm{n}=20)$ & $22.24 \pm 7.38(\mathrm{n}=20)$ & $23.78 \pm 8.99(\mathrm{n}=20)$ \\
& 8 months & $30.37 \pm 8.36^{\mathrm{a}}(\mathrm{n}=18)$ & $29.45 \pm 6.89^{\mathrm{a}}(\mathrm{n}=19)$ & $28.12 \pm 7.65^{\mathrm{a}}(\mathrm{n}=17)$ \\
& 10 months & $34.89 \pm 4.16^{\mathrm{a}}(\mathrm{n}=15)$ & $34.54 \pm 3.87^{\mathrm{a}}(\mathrm{n}=17)$ & $31.96 \pm 4.84^{\mathrm{a}}(\mathrm{n}=15)$ \\
Total cholesterol $(\mathrm{mmol} / \mathrm{l})$ & Baseline & $1.97 \pm 0.51(\mathrm{n}=20)$ & $2.01 \pm 0.46(\mathrm{n}=20)$ & $1.98 \pm 0.65(\mathrm{n}=20)$ \\
& 8 months & $11.23 \pm 1.29^{\mathrm{a}}(\mathrm{n}=18)$ & $12.26 \pm 1.32^{\mathrm{a}}(\mathrm{n}=19)$ & $11.78 \pm 1.09^{\mathrm{a}}(\mathrm{n}=17)$ \\
& 10 months & $14.67 \pm 2.23^{\mathrm{a}}(\mathrm{n}=15)$ & $15.31 \pm 2.01^{\mathrm{a}}(\mathrm{n}=17)$ & $14.56 \pm 2.65^{\mathrm{a}}(\mathrm{n}=15)$ \\
& Baseline & $1.01 \pm 0.27(\mathrm{n}=20)$ & $0.98 \pm 0.34(\mathrm{n}=20)$ & $1.02 \pm 0.36(\mathrm{n}=20)$ \\
LDL-C $($ mmol/l) & 8 months & $8.24 \pm 1.23^{\mathrm{a}}(\mathrm{n}=18)$ & $9.12 \pm 1.29^{\mathrm{a}}(\mathrm{n}=19)$ & $8.65 \pm 1.31^{\mathrm{a}}(\mathrm{n}=17)$ \\
& 10 months & $10.23 \pm 2.21^{\mathrm{a}}(\mathrm{n}=15)$ & $9.98 \pm 2.65^{\mathrm{a}}(\mathrm{n}=17)$ & $10.31 \pm 2.07^{\mathrm{a}}(\mathrm{n}=15)$ \\
& Baseline & $0.65 \pm 0.28(\mathrm{n}=20)$ & $0.64 \pm 0.31(\mathrm{n}=20)$ & $0.71 \pm 0.29(\mathrm{n}=20)$ \\
HDL-C $(\mathrm{mmol} / \mathrm{l})$ & 8 months & $2.31 \pm 0.25^{\mathrm{a}}(\mathrm{n}=18)$ & $2.41 \pm 0.22^{\mathrm{a}}(\mathrm{n}=19)$ & $2.35 \pm 0.37^{\mathrm{a}}(\mathrm{n}=17)$ \\
& 10 months & $2.65 \pm 0.31^{\mathrm{a}}(\mathrm{n}=15)$ & $2.60 \pm 0.32^{\mathrm{a}}(\mathrm{n}=17)$ & $2.59 \pm 0.29^{\mathrm{a}}(\mathrm{n}=15)$ \\
& Baseline & $0.34 \pm 0.12(\mathrm{n}=20)$ & $0.35 \pm 0.10(\mathrm{n}=20)$ & $0.37 \pm 0.12(\mathrm{n}=20)$ \\
Triglyceride $(\mathrm{mmol} / \mathrm{l})$ & 8 months & $0.33 \pm 0.10^{\mathrm{a}}(\mathrm{n}=18)$ & $0.34 \pm 0.11^{\mathrm{a}}(\mathrm{n}=19)$ & $0.38 \pm 0.13^{\mathrm{a}}(\mathrm{n}=17)$ \\
& 10 months & $0.41 \pm 0.12^{\mathrm{a}}(\mathrm{n}=15)$ & $0.39 \pm 0.13^{\mathrm{a}}(\mathrm{n}=17)$ & $0.42 \pm 0.11^{\mathrm{a}}(\mathrm{n}=15)$
\end{tabular}

${ }^{a} \mathrm{P}<0.05$ vs. baseline. 8 months group, high-fat diet for 8 months; 10 months group, Cx-37 siRNA treatment for the last 2 months of 10 months; baseline, mock-siRNA or saline treatment for the last 2 months of 10 months. Cx37, connexin 37; siRNA, small interfering RNA; LDL-C, low density lipoprotein; HDL-C, high density lipoprotein.

Table II. Changes in the percentage of plaque necrosis and volumes between the three treatment groups.

\begin{tabular}{llcr}
\hline Variable & Cx37 siRNA & Mock siRNA & Saline \\
\hline Necrotic $(\%)$ & & & $7.78 \pm 1.28$ \\
$\quad 8$ months & $7.83 \pm 1.03$ & $7.63 \pm 1.34$ & $9.01 \pm 3.02$ \\
10 months & $5.26 \pm 2.11$ & $8.79 \pm 3.36$ & $30.21 \pm 12.02$ \\
Plaque volume $\left(\mathrm{mm}^{3}\right)$ & & $32.12 \pm 11.21$ & $37.36 \pm 14.21$ \\
8 months & $31.23 \pm 10.23$ & $38.54 \pm 13.56$ & \\
10 months & $21.03 \pm 6.24$ & & \\
\hline
\end{tabular}

Values are expressed as the mean \pm standard deviation. 8 months group, high-fat diet for 8 months; 10 months group, Cx-37 siRNA treatment for the last 2 months of 10 months siRNA, small interfering RNA; Cx37, connexin 37.

Efficient transfection of lentivirus. Previous studies have shown that local virus delivery to precollar-induced abdominal aortic atherosclerosis of pigs has resulted in efficient transfection to abdominal aortic atherosclerosis (24). GFP expression provides an efficient and convenient method by which to check lentiviral transfection efficiency. Therefore, GFP was analyzed in the abdominal aortic atherosclerosis 1 week after transfection (Fig. 3A). siRNA transfection (indicated by strong green fluorescence) was observed most significantly after 2 weeks after transfection (Fig. 3B). When the study was terminated, GFP remained weakly visible, two months after transfection (Fig. 3C). These results demonstrated the efficiency of the in vivo transfection of siRNA lentiviruses in the abdominal aortic atherosclerosis. Local transfection of the virus did not affect the normal functioning of the animals and did not result in weight change $(34.89+4.16 \mathrm{~kg}$ in transfected pigs vs. $34.54+3.87 \mathrm{~kg}$ in mock-siRNA and $31.96 \pm 4.84 \mathrm{~kg}$ in saline).

Gene silencing in vivo. To evaluate the efficacy of lentivirus-mediated gene silencing in vivo on abdominal aortic atherosclerosis of pigs, Cx37 mRNA and protein expression levels were analyzed by qPCR and western blot analyses. Cx37 mRNA levels in the Cx37 siRNA group were decreased to $38 \%$ as compared with those in the mock-siRNA group, which were decreased to $60 \%$, and to $63 \%$ in the saline group $(\mathrm{P}<0.05)$ (Figs. 4 and 5). The mock group showed no significant change in Cx37 mRNA expression as compared with the control group. Western blot analysis indicated that $\mathrm{Cx} 37$ protein was lowest in the Cx37-RNAi group as compared with the mock and 


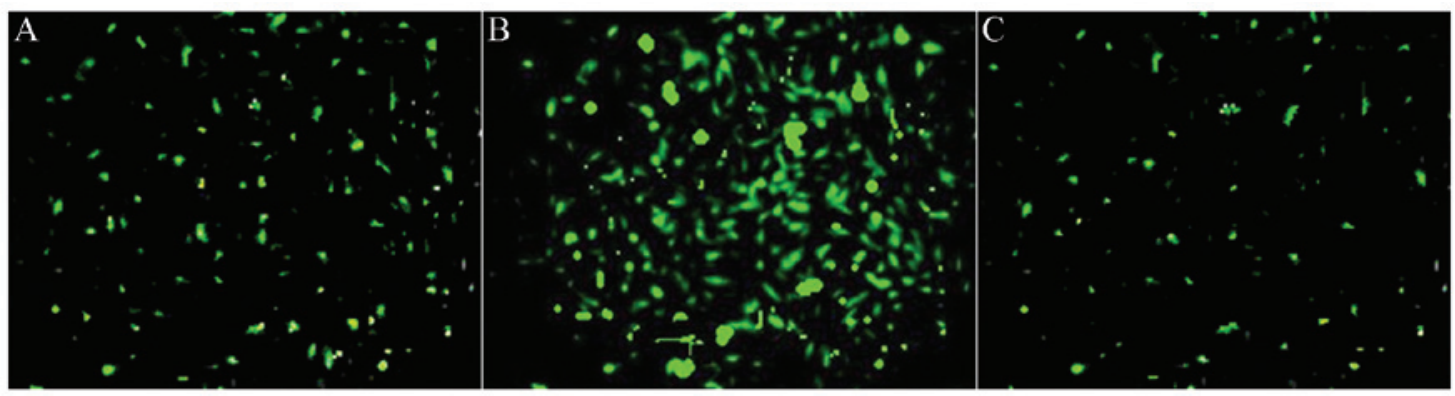

Figure 3. Detection of green fluorescence protein in aortic atherosclerosis of pigs in Cx-37 siRNA group (magnification, x200). (A) One week; (B) two weeks; (C) two months after transfection.

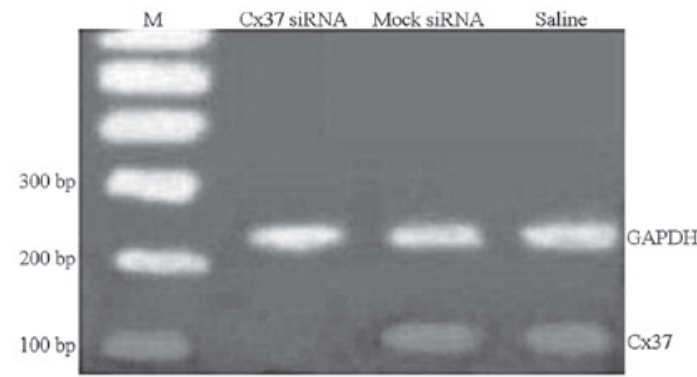

Figure 4. Quantitative polymerase chain reaction gel electrophoresis. Bp, base pairs; Cx37, connexin 37; siRNA, small interfering RNA.

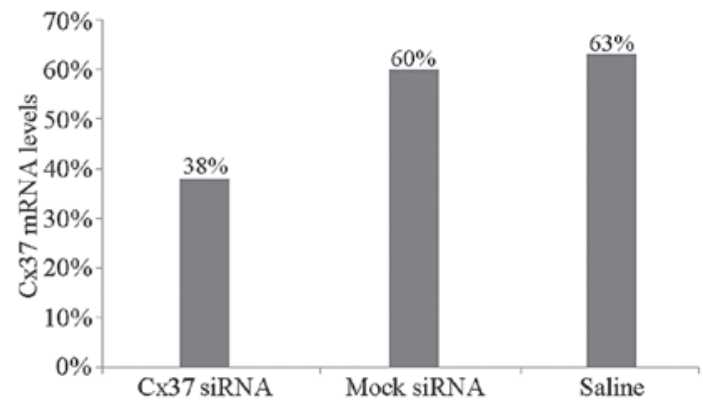

Figure 5. Comparison of Cx37 mRNA levels between the three treatment groups. Cx37, connexin 37; siRNA, small interfering RNA; mRNA, messenger RNA.

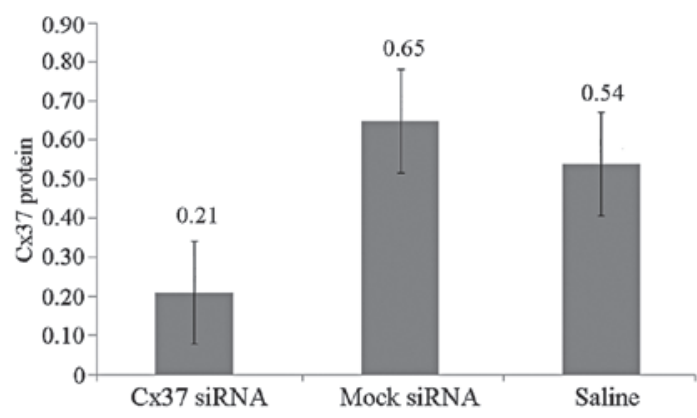

Figure 6. Comparison of the $\mathrm{Cx} 37$ protein levels bewteen the three treatment groups. Cx37, connexin 37; siRNA, small interfering RNA.

saline-treated groups $(0.21 \pm 0.07$ vs. $0.65 \pm 0.06$ vs. $0.54 \pm 0.07)$ (Fig. 6). Therefore, the local application of siRNA-lentivirus efficiently silenced the target mRNA.

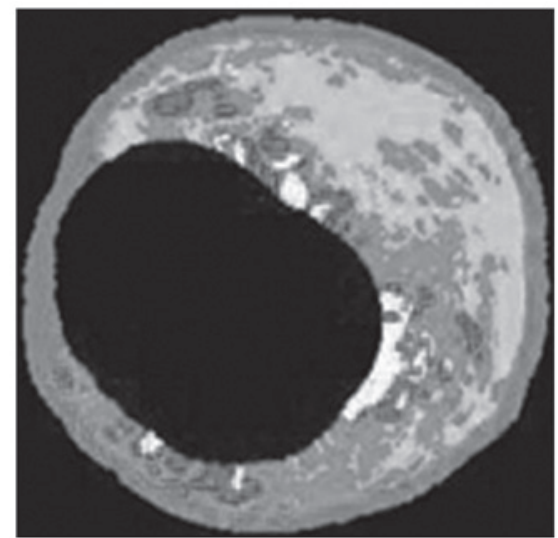

Figure 7. Virtual histology of a plaque of aortic atherosclerosis of pigs. Virtual histology of a plaque of aortic atherosclerosis of pigs in Cx-37 siRNA group (magnification, $\mathrm{x} 200$ ).

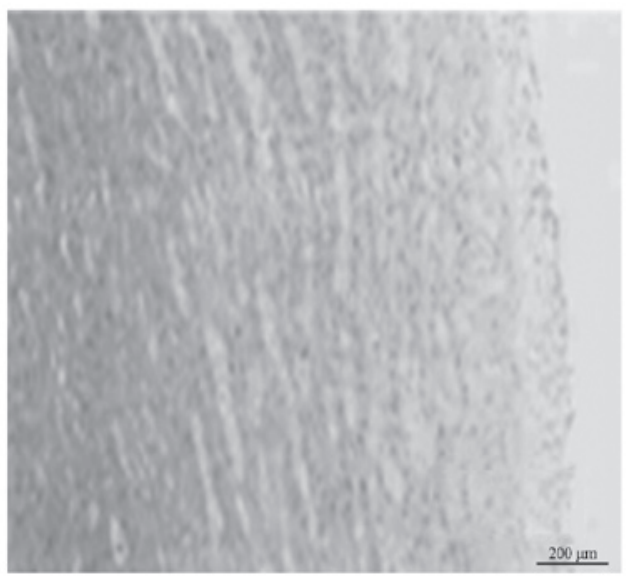

Figure 8. Plaque of aortic atherosclerosis in pigs. Plaque of aortic atherosclerosis in pigs in $\mathrm{Cx}-37 \mathrm{siRNA}$ group (magnification, $\mathrm{x} 200$ ).

Effects of CX37 siRNA on atherosclerosis plaque. The percentage of plaque necrosis following 10 months (after injection Cx37 siRNA) decreased in the Cx37 siRNA groups as compared with that following eight months (prior to injection of Cx37 siRNA) $(5.26 \pm 2.11$ vs. $7.83 \pm 1.03 \%, \mathrm{P}<0.05)$. In the mock-siRNA and saline groups, no differences in percentages of plaque necrosis following eight months were observed $(\mathrm{P}=0.074$ and 0.061 , respectively). In the $\mathrm{Cx} 37$ siRNA group, plaque volumes at 10 months (following RNAi) decreased as compared with those 
at eight months (prior to RNAi) $(21.03 \pm 6.24$ vs. $31.23 \pm 10.23$, $\mathrm{P}<0.01)$. By contrast, plaque volumes increased between 8 and 10 months $\left(38.54 \pm 13.56\right.$ vs. $32.12 \pm 11.21 \mathrm{~mm}^{3}, 37.36 \pm 14.21$ vs. $30.21 \pm 12.02 \mathrm{~mm}^{3}, \mathrm{P}=0.031$ and $\mathrm{P}=0.027$, respectively) in the mock siRNA and saline groups. Changes in the percentages of plaque necrosis and plaque volumes in groups are shown in Table II and Figs. 7 and 8.

\section{Discussion}

The frequency of the $\mathrm{C}$ allele at base pair 1019 of the Cx37 gene in patients with coronary heart disease was observed to be significantly higher as compared with that of healthy controls (17). The present in vivo study demonstrated that $\mathrm{Cx} 37$ gene interference in the pig resulted in a reduced volume but improved the stability of the atherosclerosis plaque. To the best of our knowledge, the present study was the first to report the effect of Cx37 RNAi in atherosclerotic plaques.

Atherosclerosis is a chronic inflammatory disease of the arterial wall $(25,26)$, which has been associated with numerous genetic factors (27). Previous studies have demonstrated that Cx37 gene polymorphism is a risk factor of coronary heart disease. Cx37 and associated genes may therefore be suitable therapeutic targets in atherosclerosis, since they have been shown to be important in recognizing highly evolutionarily conserved molecular motifs in pathogens. Previous studies demonstrated that $\mathrm{Cx} 37$ has a significant role in atherosclerosis $(9,17)$. Therefore, in the present study, Cx37 genes were selected as therapeutic targets for atherosclerotic plaques.

MicroRNAs (miRNAs), a class of short RNAs, are involved in numerous biological processes and the development of human disease through specific posttranscriptional downregulation of gene expression (28). RNAi is an effective method for selectively silencing mRNA for a wide range of proteins. This method has been applied in several diseases for gene intervention. Although a number of delivery approaches are available, significant challenges remain, including the success rate, safety and off-target effects of the RNA in vivo. To overcome these limitations, a lentivirus expression cassette was used to increase transfection efficiency. Lentiviral vector-delivered siRNAs have been previously used to successfully silence gene function in primary mammalian cells, stem cells and rabbits (29). In the present study, lentivirus-siRNA was delivered site-specifically to the targeted plaque site at high titers (i.e., by instilling the lentivirus suspension into the pigs' abdominal aorta artery). The efficacy of this method was confirmed by the observation of GFP fluorescence in the abdominal aortic plaque during the first and second week following transfection. Stronger fluorescence was observed two months following transfection. No adverse effects were observed in the pigs used in the present study. In addition, no significant differences in body weight among the Cx37 siRNA group, mock siRNA group and saline group were found, which indicated the safety of virus transfection in these animals. The absence of significant differences in the serum lipid among the Cx37 siRNA, mock siRNA and saline groups excluded the possibility that the therapeutic effects in the Cx37 siRNA group were caused by nonspecific stimulation. However, following the two-month Cx37 siRNA injection, the plaque necrosis and the plaque volume percentages decreased. However, no differences in the mock-siRNA and saline groups in percentages of plaque necrosis from injection of mock siRNA and saline were observed. By contrast, plaque volume increased in the mock siRNA and saline groups. Therefore, lentiviral vectors expressing siRNA comprise a safe, efficient and specific tool to study gene function and therapy.

The effects of interference of Cx37 genes on advanced atherosclerotic lesions have not been investigated previously. The present study demonstrated that $\mathrm{Cx} 37$ is critical in the progression of atherosclerosis. The pigs treated with $\mathrm{Cx} 37$ siRNA consistently exhibited lipid levels similar to those of the mock and saline subgroups, and no statistically significant differences were observed prior to and following treatment in the three groups. The percentage of plaque necrosis and plaque volume in the Cx37 siRNA group post treatment were lower as compared with those prior to treatment. Both values in the control and mock subgroups were higher than those prior to treatment. Inhibited metabolism of active macrophages in the plaques may explain the attenuation of atherosclerosis induced by $\mathrm{Cx} 37$ gene interference.

The mechanisms underlying the therapeutic effects of Cx37 are currently not fully understood; however, they may be associated with its recognition patterns. If an SNP in the Cx37 gene causes a cytosine-to-thymine replacement at position 1019 (C1019T), a nonconservative amino acid replacement of proline with serine, occurs in the regulatory $\mathrm{C}$-terminus of the Cx37 protein (P319S). This amino acid replacement may lead to functional changes of the protein and different responses to regulatory mechanisms, such as phosphorylation. The creation of a new phosphorylation site may result in a greater capacity for modulating the function of gap junctions that are regulated by this protein. This may modify endothelial cell function and lead to susceptibility to cardiovascular diseases. Recent studies have demonstrated that Cx37 is expressed in endothelial cells, monocytes/macrophages and platelets (1). The electrophysiological characteristics determined in the present study are similar to but distinct from previously characterized connexins (30). However, the effects of Cx37 siRNA on atherosclerosis plaques and the mechanisms of $\mathrm{Cx} 37$ action remain to be identified.

In conclusion, lentivirus-mediated siRNA can be used to efficiently knock down $\mathrm{Cx} 37$ genes in abdominal aortic plaques of pigs fed with a high-fat diet.

\section{References}

1. Pfenniger A, Chanson M and Kwak BR: Connexins in atherosclerosis. Biochim Biophys Acta 1828: 157-166, 2013.

2. Otsuka F, Yahagi K, Sakakura K and Virmani R: Why is the mammary artery so special and what protects it from atherosclerosis. Ann Cardiothorac Surg 2: 519-526, 2013.

3. Steinberg D: In Celebration of the 100th anniversary of the lipid hypothesis of atherosclerosis. J Lipid Res 54: 2946-2949, 2013.

4. Xu Y, Liu Q, Xu Y, et al: Rutaecarpine suppresses atherosclerosis in ApoE-/- mice through up-regulating ABCA1 and SR-BI within RCT. J Lipid Res 55: 1634-1647, 2014.

5. Saez JC, Berthoud VM, Branes MC, Martinez AD and Beyer EC: Plasma membrane channels formed by connexins: their regulation and functions. Physiol Rev 83: 1359-1400, 2003.

6. Fang JS, Angelov SN, Simon AM and Burt JM: Cx37 deletion enhances vascular growth and facilitates ischemic limb recovery. Am J Physiol Heart Circ Physiol 301: H1872-H1881, 2011.

7. Kanady JD, Dellinger MT, Munger SJ, Witte MH and Simon AM: Connexin37 and Connexin 43 deficiencies in mice disrupt lymphatic valve development and result in lymphatic disorders including lymphedema and chylothorax. Dev Biol 354: 253-266, 2011. 
8. Morel S and Kwak BR: Roles of connexins in atherosclerosis and ischemia-reperfusion injury. Curr Pharm Biotechnol 13: 17-26, 2012.

9. Guo SX, Yang ZY, Wang RX, Yang Y, Cao HM and Zhang T: Association between C1019T polymorphism of the connexin37 gene and coronary heart disease in patients with in-stent restenosis. Exp Ther Med 5: 539-544, 2013.

10. Boerma M,Forsberg L, Van Zeijl L, et al: A genetic polymorphism in connexin 37 as a prognostic marker for atherosclerotic plaque development. J Intern Med 246: 211-218, 1999.

11. Yeh HI, Chou Y, Liu HF, Chang SC and Tsai CH: Connexin37 gene polymorphism and coronary artery disease in Taiwan. Int J Cardiol 81: 251-255, 2001.

12. Han YL, Xi SY, Zhang XL, Yan CH, Yang Y and Kang J: Association of C1019T polymorphism in the Connexin37 gene and coronary artery disease in Chinese Han population. Zhonghua Yi Xue Za Zhi 87: 100-104, 2007 (In Chinese).

13. Wong CW, Christen T, Pfenniger A, James RW and Kwak BR: Do allelic variants of the connexin37 1019 gene polymorphism differentially predict for coronary artery disease and myocardial infarction? Atherosclorosis 191: 355-361, 2007.

14. Yamada Y, Izawa H, Ichihara S, et al: Prediction of the risk of myocardial infarction from polymorphisms in candidate genes. N Engl J Med 347: 1916-1923, 2002.

15. Listi F, Candore G, Lio D, et al: Association between C1019T polymorphism of connexin 37 and acute myocardial infarction: a study in patients from Sicily. Int J Cardiol 102: 269-271, 2005.

16. Seifi M, Fallah S, Ghasemi A, Aghajani H, Razaghi M and Danaei N: Mutations of the connexin 37 and 40 gap-junction genes in patients with acute myocardial infarction. Clin Lab 59: 343-348, 2013

17. Pfenniger A, Wong C, Sutter E, et al: Shear stress modulates the expression of the atheroprotective protein $\mathrm{Cx} 37$ in endothelial cells. J Mol Cell Cardiol 53: 299-309, 2012.

18. Kumari SS, Varadaraj K, Valiunas V, et al: Functional expression and biophysical properties of polymorphic variants of the human gap junction protein connexin37. Biochem Biophys Res Commun 274: 216-224, 2000.
19. Schecter AD, Rollins BJ, Zhang YJ, et al: Tissue factor is induced by monocyte chemoattractant protein-1 in human aortic smooth muscle and THP-1 cells. J Biol Chem 272: 28568-28573, 1997.

20. Moghadasian MH: Experimental atherosclerosis: a historical overview. Life Sci 70: 855-865, 2002.

21. Reinhard K, Rougier JS, Ogrodnik J and Abriel $\mathrm{H}$ Electrophysiological properties of mouse and epitope-tagged human cardiac sodium channel Na v1.5 expressed in HEK 293 cells. F1000Res 2: 48, 2013.

22. Yang JM, Wang Y, Qi LH, et al: Combinatorial interference of toll-like receptor 2 and 4 synergistically stabilizes atherosclerotic plaque in apolipoprotein E-knockout mice. J Cell Mol Med 15: 602-611, 2011.

23. Chapman MJ, Mills GL and Ledford JH: The distribution and partial characterization of the serum apolipoproteins in the guinea pig. Biochem J 149: 423-436, 1975.

24. Qi LH, Wang Y, Gao F, et al: Enhanced stabilization of atherosclerotic plaques in apolipoprotein E-knockout mice by combinatorial Toll-like receptor-1 and -2 gene silencing. Hum Gene Ther 20: 739-750, 2009.

25. Thompson PL, Nidorf SM and Eikelboom J: Targeting the unstable plaque in acute coronary syndromes. Clin Ther 35: 1099-1107, 2013

26. Mallavia B, Recio C, Oguiza A, et al: Peptide inhibitor of NF- $\kappa$ B translocation ameliorates experimental atherosclerosis. Am J Pathol 182: 1910-1921, 2013.

27. Zaina S and Lund G: Atherosclerosis: cell biology and lipoproteins - panoramic views of DNA methylation landscapes of atherosclerosis. Curr Opin Lipidol 24: 369-370, 2013.

28. Menghini R, Casagrande V and Federici M: MicroRNAs in endothelial senescence and atherosclerosis. J Cardiovasc Transl Res 6: 924-930, 2013.

29. Maraghechi P, Hiripi L, Toth G, Bontovics B, Bosze Z and Gocza E: Discovery of pluripotency-associated microRNAs in rabbit preimplantation embryos and embryonic stem-like cells. Reproduction 145: 421-437, 2013.

30. Reed KE, Westphale EM, Larson DM, Wang HZ, Veenstra RD and Beyer EC: Molecular cloning and functional expression of human connexin37, an endothelial cell gap junction protein. J Clin Invest 91: 997-1004, 1993 